
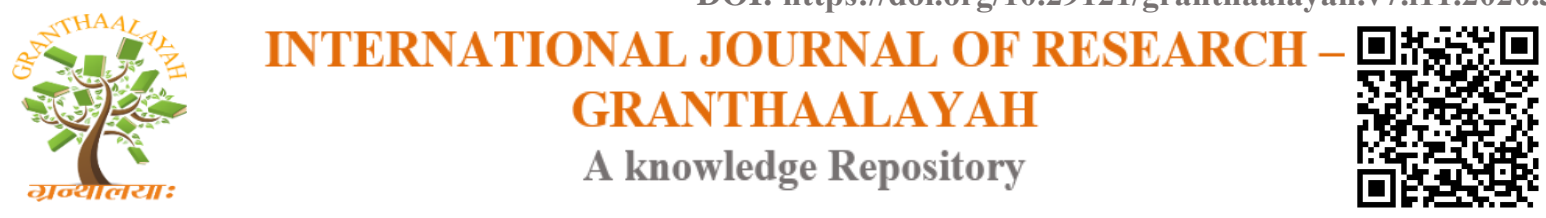

Social

\title{
SOCIAL AND FAMILIAL MALADJUSTMENT: SOCIAL REPRESENTATIONS IN CLOSED EDUCATIONAL CENTER FOR TEENAGERS AND YOUTH
}

\author{
Anagonou L ${ }^{1}$, Saria B ${ }^{2}$, Klikpo E ${ }^{3}$, Salifou S ${ }^{4}$, Houinou Ebo B ${ }^{5}$, Fiossi Kpadonou E ${ }^{1}$ \\ ${ }^{1}$ University of Abomey-Calavi, Faculty of health science, Department of Mental Health, CHU- \\ MEL, Cotonou, Benin \\ ${ }^{2}$ Pole mental health, Hospital of West Guyana, Saint Laurent-Du-Maroni, French Guyana \\ ${ }^{3}$ University of Abomey-Calavi, Faculty of health science, Department of mental health, \\ CNHUP, Cotonou, Benin. \\ ${ }^{4}$ University of Lome, Faculty of health science, University clinic of psychiatry and Clinical \\ Psychology, CHU-Sylvanus Olympio, Lomé, Togo \\ ${ }^{5}$ Departmental university hospital center Borgou-Alibori, Parakou, Benin
}

\begin{abstract}
Social and familial maladjustment is the inability to conform to a group's habits and norms and to participate in its activities and productions. The purpose of this study is to study the social representations of the social and familial maladjustment of adolescents and young people.

This is a case study, using a mixed method essentially qualitative, set in a closed educational center in the Department of Littoral in Benin. The study concerned adolescents and young people admitted to the center and their referents. The respondents in the target population were all male and aged 10 to 23 with an average age of 18 years.

The social representations of maladjustment, according to young people and their referents are similar. They concern social disqualification, inadequate educational attitudes, the absence of familial model, educational failure linked to adolescents or young people and mystical-religious representations. Adolescents and young people define themselves as deviants while their referents define them as delinquents.

This create an insecurity feeling and a need to protect society. Adults have to integrate themselves earlier in the prevention of this phenomenon with the help and /or child psychiatrist lead.
\end{abstract}

Keywords: Social and Familial Maladjustment; Social Representations; Adolescents; Youth; Referents; Closed Educational Center.

Cite This Article: Anagonou L, Saria B, Klikpo E, Salifou S, Houinou Ebo B, and Fiossi Kpadonou E. (2019). "SOCIAL AND FAMILIAL MALADJUSTMENT: SOCIAL REPRESENTATIONS IN CLOSED EDUCATIONAL CENTER FOR TEENAGERS AND YOUTH.” International Journal of Research - Granthaalayah, 7(11), 187-194. 10.29121/granthaalayah.v7.111.2020.352. 


\section{Introduction}

Like world wise, social and familial maladjustment in teenagers and young persons has been a nowadays a real concern in Benin. The maladjusted, from the point of view of social measures, is a person who seems to be the one who can't be educated and withdraw himself from the requirement and norms of society [1]. Among teenagers and young maladjusted, there are vulnerable and fragile persons, persons who committed offences, but who need some alternative measures as admission into a foster center. The main focus of these center is to educate them, help them to a better socialization and facilitate a good social and professional reinsertion. These children, often with a complicated early childhood development, have most of the time an insecure attachment. The effectiveness of the support intervention can be fragilized by the type of interaction they can put in place, and thus, what they can resend to the referents. From referents perception of the phenomenon, will depend their attitude and their self-perceived of the meaning of their role, along the care process. Because, conducts and practices within the society are dictated by social representations. This study has the main focus of study the different elements of social representation of social and familial maladjustment of referents, those of teenagers and young from a closed educational center of Littoral department in Benin.

\section{Material and Method}

The study combined quantitative and qualitative methods. It was carried out in a closed educational center of Littoral, the department of Benin where the economic capital is located in 2014. The study involved 31 adolescents and young people and 4 adults referents. We used an exhaustive sampling for the selection of adolescents and young people, while for the referent group, the sampling followed a reasoned choice. Data were collected by participated observation and semidirective interview oriented on the collection of sociodemographic data and the content of social representations. Sociodemographic data were extracted for quantitative analysis, using SPSS version 20.0. The qualitative data were analyzed based on thematic content, using mainly essential themes, but with the flexibility for emergence of new themes. Participation in the study was voluntary, with oral consent; respondents could leave the research process at any time, without prejudice.

\section{Results}

\subsection{Social and Demographic Characteristics, Familial Ecology of Teenagers and Young Adult Participants}

The surveyed, were all male and aged 10 to 23 years old. The mean age is 18 years old; $15-19$ years old bracket was the most representative. $80 \%$ of the participant have dropped school early on. The level of education in this population were primary and secondary school with $48 \%$ for each. Teenagers and youth who have their parents divorced or separated were $22.6 \%$ of the participants. $48.3 \%$ were orphans from mother and/or father; 16 participants declared that their parents alive or deceased have been in polygamy $(51.6 \%)$. The participant's families were composed at least of 4 children $(71 \%$ ) (see Table I). 
Table1: Distribution of teenagers and young adults participants according to the social and demographic characteristic and familial ecology

\begin{tabular}{|l|c|c|}
\hline \multicolumn{2}{|c|}{ n } & \% \\
\hline \multicolumn{2}{|c|}{ Social and demographic characteristics } \\
\hline Age & & \\
\hline $10-14$ years old & 6 & 19.4 \\
\hline 15-19 years old & 21 & 67.7 \\
\hline$\geq 20$ years old & 4 & 12.9 \\
\hline School level & & \\
\hline Primary & 15 & 48.4 \\
\hline Secondary & 15 & 48.4 \\
\hline Uneducated & 4 & 3.2 \\
\hline Scolary status & & \\
\hline Dropped school & 25 & 80.6 \\
\hline Still at school & 6 & 19.4 \\
\hline \multicolumn{3}{|c|}{ Familial ecology } \\
\hline Familial situation & & \\
\hline Father and/or mother deceased & 15 & 48.3 \\
\hline Parents living together & 7 & 22.6 \\
\hline Parents divorced or separated & 7 & 22.6 \\
\hline Parents with not living together & 2 & 6.5 \\
\hline Matrimonial situation of parents & & \\
\hline Monogam & 15 & 48.4 \\
\hline Polygam & 16 & 51.6 \\
\hline Siblings & & \\
\hline$\geq 4$ children & 22 & 71.0 \\
\hline 3 children & 5 & 16.1 \\
\hline 2 children & 4 & 12.9 \\
\hline
\end{tabular}

\subsection{Society, Law and Offences, Sanctions}

The participants have committed the offences of stealing, of complicity on stealing in $80.6 \%$ of cases. The motives of the acting out, they evoked, were about fulfilling basic daily life needs $(\mathrm{n}=$ $25 ; 45.1 \%) .67 .7 \%(n=21)$ of the participants had been law offenders in the past before entering the education center. From the 31 participants, 21 have been in placement before, $67.7 \% ; 12(38.7 \%$ were not living anymore with their biological parents when they committed the offences or when they have been admitted in the detention center as showed in table II.

Table2: Distribution of participants according to Society, Law and offences

\begin{tabular}{|c|c|c|}
\hline \multicolumn{3}{|l|}{ Society, laws, offences } \\
\hline \multicolumn{3}{|l|}{ Society, laws, offences } \\
\hline Reasons of placement or offences committed & & \\
\hline Stealing or complicity of stealing & 25 & 80.6 \\
\hline Intentional injury & 3 & 9.7 \\
\hline Rape & 2 & 6.5 \\
\hline
\end{tabular}




\begin{tabular}{|l|c|c|}
\hline Involuntary injury & 1 & 3.2 \\
\hline Justification of offence & & \\
\hline Fufill daily need & 14 & 45.1 \\
\hline No justification & 13 & 41.9 \\
\hline Peers influence & 2 & 6.5 \\
\hline Defence of parent & 2 & 6.5 \\
\hline \multicolumn{2}{|c|}{ Current and past life environment } \\
\hline Living place before placement & & \\
\hline Father and/or mother house & 19 & 61.3 \\
\hline Member of family house & 8 & 25.8 \\
\hline Tutor with no family relationship house & 4 & 12.9 \\
\hline Duration in placement center & & \\
\hline$\geq 24$ months & 17 & 54.8 \\
\hline$<24$ months & 5 & 16.1 \\
\hline$\leq 12$ months & 9 & 29.0 \\
\hline
\end{tabular}

\subsection{Different Elements of Social Representation on the Social and Familial Maladjustment}

They have been studied from the social representation of maladjusted, and those related to social and familial maladjustment.

\subsubsection{Social Representation of the Social and Familial Maladjustment}

The analysis of the social representation enabled us to find out some themes.

\section{The Social Disqualification}

Poverty was the main cause evoked by the participants for their social maladjustment. The characteristics of the target population point this notion of poverty.

School dropped have been found with $80 \%$ of the participants; $45.1 \%$ justified their offence by the need of fulfilment of daily basic living needs.

\section{The Inadequacy of Educational Attitudes}

The laxness, physical punishment instead of empathy, hearing, negotiation and help for understanding, have been reported by the participants as a reason for social and familial maladjustment. This fact can provoke fugue, wandering and bad frequentations.

\section{Non-Existence of Familial Model}

The loss of family model, educational instability with multiple placements were the characteristics of the target population in the study. The youngs found themselves in a premature responsibility taking. To face their living needs, they need to work, thus the youngs and referents suggested education and professional training as solution. 


\section{Mystical and Religious Representations}

According to some young participant in the study, spirit possession could be the reason of maladjustment relating to the manifestations and consequences (antisocial conduct disorders). For this, the traditional therapists are involved in the management of the symptoms, letting the social management for educational centers.

\section{Educational Fail Elated to Teenagers and Young Adults}

For most of the young participants, the reason of the maladjustment is sometimes exclusively personal. Some participant displayed disobedience toward their parents, put themselves in some idleness and act excessive ambition.

The referent also declared that the responsibility is sometimes exclusively from youngs.

\subsubsection{Social Representation of the Maladjusted}

From the definition of the state of social-maladjusted, two themes have been pointed out: the deviant and the delinquent.

\section{The Deviant}

The participants defined themselves as deviants, not delinquents. They expressed themselves using the opposite of what the users of the centre and the population in general say and think about them.

The evocation of consequences of their behaviour was centered on their own person. The deprivation of freedom $(n=23)$ and the death $(n=29)$ have been the consequences reported by the young's. The family reject, toxicomania and physical degradation have also been evoked.

\section{The Delinquent}

The referents related delinquent by the lazy, the recidivist in term of bad behaviour, the stubborn. For them the delinquent like lot of foods and sex. The first consequence evoked by the referents is "the feeling of insecurity, the loss of peace" for the person in his individuality and also for the community in general.

The second consequence evoked is the augmentation of criminality with the impact on social and economic development. Contamination "to children of their environment", and belongings destructions have been evoked. These consequences have been more seen as repercussion on the society and on its members in general.

\section{Discussion}

\subsection{Socials Representations of the Social Maladjustment}

The social and familial maladjustment representations according to the youngs adults is about social disqualification, the inadequacy of educational attitude, the non-existence of familial model, the mystic and religious representations and educational fail. These same representations have been stressed out by the referents, except the mystic and religious representations, that has not reported but that exist in the speech of the users of the center and to which specific attitudes have been opposed. 
The social disqualification, the inadequacy of the educational attitude, the non-existence of familial model and the educational fail have been reported by many authors.

Familial environment could explain, at least a part of the emergence of deluctuous acts, this at many levels: <<the familial disadvantaged >>in which raises the family, the educational practices and the constraint on the child, the bonding that the minor experienced with his parents.

The poor social and economic condition and environment enables the emergence of conduct disorders. Doise in his study about the social representation of delinquency in young people found out the social inequality as first cause [2].

According to Dumas, there is a relation between antisocial behaviour and the social and economic status (especially the precariousness). This relationship is particularly enhanced in presence of other factors of risk like parents-child conflicts [3].

For a harmonious development, the teenagers and young adults need to be surrounded by safe adults especially their parents. To be able to transmit their role, these must have an acceptable condition of living.

For almost the half (45.1\% of youngs of our sample, the justification of behaviour that lead to placement is the non-satisfaction of basic living needs. The offences and stealing have been reported by the youngs as symptoms behaviours. These constituted $80.6 \%$ of offences that motivated the placement.

According to the meaning, the robbery can be classified in compulsive robbery, impulsive robbery, initiatory robbery or utilitarian robbery. According to Marcelli [4], the robbery represents a delinquent conduct the most frequent in teenage and could be responsible of a large part of the augmentation of the statistic about delinquency.

Childpro in Benin stated that almost all of the young boys in conflict with law, has been for robbery [5]. Roche who, in 2010, has particularly studied the influence of the social and economic situation of the parents about the type of offences, found out that the youngs who had their parents as workers or employees, have been frequently implicated in some kind of acts of street delinquency, like degradation or aggravated robbery [6].

The fulfilment of essential needs evoked in our sample, could be explained, by the specificity of our population with social, cultural and economic nonfavourable and without the existence of social support system for families living in precarity.

It is found that $38.7 \%$ of the participants were not living with their biological parents before their incarceration or placement and $67.7 \%$ have been at least once in placement in their life. Similarly, more than the half $(51.6 \%)$ of the family of our sample were polygamy and more than a third $(35,5 \%)$ of the families were with at least 4 children.

In contrast with what was usual in the past, the polygamy nowadays, with the occidental civilisation and modernism has changed its interface. It leads to many conflicts between parental 
couples, intrafamilial violence, rivalries between co-wives and between children, the neglect, the absence of cohesion in the family.

In the big sized families, there is a lack of parental control and capacity of supervision and the children are more likely to develop conduct disorder. Roche, in 2010 in Canada confirmed that the delinquency between young was more in young from big size families [6]. The lack of affective security and education, instability of attachment figure, different forms of parental neglect and abuse (physical and mental), interferes and has a certain influence in the development on conduct disorders.

About the mystic and religious representations, they have not yet been object of scientist study concerning the topic of social and familial maladjustment. In Africa and particularly in Benin, every stressful situation is attributed to an external cause. Traditional african concepts are linked to cosmogonic references. The quality of relation between human and these elements, determine order and disorder, the state of health and sickness. The situations considered uncomfortable are never only related to immediate personal, social, family or circumstantial determinants, that can be identified or not.

This explains the place of mystic and religious beliefs in the representations and the search of consequence attitudes every time this system of comprehension is seek. Many studies conducted in Africa about mental disorders showed in fact that the causes said natural, cosmogonic are presents in etiological conceptions. Disorders are due to mystic, the non-living creatures (ghosts, ancestry) or divine in which luck has little place [7].

\subsection{Social Representation of the Maladjusted}

The maladjusted has generated two types of social representations among the population surveyed.

The youngs described themselves as people who took a deviant pathway because of the personal and/or familial difficulties. This result confirmed those found by authors who stated that few of the youngs identified themselves as delinquents.

Our results are similar with those from Delens-Ravier [8] who said, the most part of people who committed offences refused to identify themselves with the name that the juridical system gives them, because they believe that their behaviours are a part of learning process.

The behaviour that they described is about the fraud or robbery or aggressive conducts in which people have been threatened in the physical state, the breach of the law.

The consequences of these acts stated by youngs are centered on their own person, in form of privation and death.

Their referents described the same conducts and add the conduct where material have been destroyed. The consequences of these acts mentioned by referents are focused on the impacts on the society like insecurity feel, destruction of things and the behaviour contamination to other young persons. The society is seen as threatened. Thus, the youngs participants are considerate by 
referents as determiners of physic and psychologic destruction, peace and morals, individuals (including their own person) society and environment.

According to referents, as well as their families who abandoned them, the youngs are considerate as delinquents. Their focus is on the act of delinquency and its negatives implications especially aggressive conducts. People aggressed physically are $12.9 \%$ of the sample. According to Marcelli, this represents in France $9.0 \%$ of total offences. In the cohort of Childpro in Benin this was $85.7 \%$ of offences committed by the boys and $14.3 \%$ of offences committed by girls.

According to Mucchielli about the feeling of insecurity because of violent acts, $24 \%$ of participants have expressed a feeling of insecurity with the progression of delinquency of young people [10]. These aggressive conducts can directly threaten their own wellbeing and affect seriously their neighbourhood. This explain their difficulty for social insertion.

\section{Conclusion}

The social representations of social and familial maladjustment by the youngs participants in one hand and by the referents on the other hand has some similarities. There are few differences at the level of social representation of the maladjusted according to the thoughts of the youngs and the referents. The referents representation has a negative meaning focused on judgment about values and is not focused on the difficulties faced by the youngs. For the referents these youngs are delinquent whereas these define themselves as deviants. These enable a feeling of insecurity and a need to protect the population against them. Adults role is to integrate earlier in the prevention with the help and /or child psychiatrist lead.

\section{References}

[1] CUSSON M. The resocialization of young delinquent. Press University of Montreal, 2005. $160 \mathrm{p}$

[2] DOISE W. Social representation and causes of delinquency in young. Deviances and society, 1987; 11(2): 153-162

[3] DUMAS JE. Psychopathology of child and teenagers. 4th edition. Brucellas: de Boeck Superior; 2013, 783p

[4] MARCELLI D, BRACONNIER A. Adolescence and psychopathology.7th edition. Paris: Elsevier Masson; 2011, 689p

[5] CHILDPRO. Situation of vulnerable child in Benin. UNICEF, 2010. $110 \mathrm{p}$

[6] ROCHE S. Study on delinquency self-declared of young. Foundation MAIF, 2010. 125p

[7] SCHEID F. Social Representations mental disorders. Treaties of Psychiatry 37-725-E-10, EMC 1991. $15 \mathrm{p}$

[8] DELENS-RAVIER I. From a young court to placement in private institution: words and strategies, Press of University of Québec. p 179-202

[9] WIDMER E. From insecurity feeling to representations of delinquency. Deviance and Society. 2004; 28(2): 141-157

*Corresponding author.

E-mail address: luccea2 @gmail.com 